\title{
AVALIAÇÃO DA APRENDIZAGEM ESCOLAR NUMA VISÃO DE ARTICULAÇÃO COM OS PROCESSOS DE PLANEJAMENTO E DE IMPLEMENTAÇÃO DE ENSINO-APRENDIZAGEM
}

TeLMA MiLDNER $^{1}$

\section{A avaliação da aprendizagem numa perspectiva de educação conservadora}

A educação formal estrutura-se, convencionalmente, através da seriação escolar, a qual se manifesta por meio de processos de ensino e de aprendizagem que centram a educação formal em torno do desenvolvimento intelectual do grupo e por grupo, ignorando tanto o desenvolvimento global da personalidade, em suas dimensões - social, emocional, física - bem como a existência de características e necessidades individuais de desenvolvimento, de ensino e de aprendizagem, que interferem na formação do cidadão autônomo e democrático (Governo do Estado de Pernambuco, 1996a; Mildner, 1996). Nessa perspectiva, a maximização de resultados médios globais de aprendizagem constitui, geralmente, um indicador da qualidade de ensino, enquanto os processos de

1 Departamento de Psicologia e Orientação Educacionais, Centro de Educação, Universidade Federal de Pernambuco. 
ensino-aprendizagem e da avaliação da aprendizagem são planejados e são processados em função de ideais de alunos médios, hipotéticos, tanto como pessoas quanto como alunos, indivíduos médios inexistentes em universos reais de alunos, tão somente definidos por médias aritméticas.

Por princípio, a seriação escolar consiste no agrupamento de alunos por idade cronológica em salas de aula, numa suposta correspondente divisão do currículo em séries, os quais são realizados com base em expectativas teórico-normativas, de acordo com a suposição de que todos os indivíduos, com determinada idade, possuem necessidades, capacidades, habilidades e conhecimentos semelhantes. Mais ainda, a pedagogia processada centra-se geralmente em conteúdos de ensino informativos e na memorização mecânica e atomística dos conhecimentos sociocultural e historicamente acumulados, constituindo o cerne do processo de ensino-aprendizagem. As estratégias de decisão pedagógica reclamam apenas a adequação dos alunos aos tratamentos de instrução, enquanto essas estratégias e as metodologias de ensino-aprendizagem são apenas expressão do que as instituições resolvem adotar conforme as suas próprias conveniências e preferências. $E$ o processo de avaliação da aprendizagem é realizado segundo uma concepção e utilização equivocadas de avaliação, posto que tão somente praticada em termos da mensuração e da verificação de desempenhos manifestos de aprendizagem: "... a avaliação da aprendizagem usualmente tem tido a função de estabelecer uma classificação do educando, expressa em sua aprovação ou reprovação [e seu] uso tem se encerrado na obtenção e registro da configuração da aprendizagem do educando, nada decorrendo daí." (Luckesi, 1995, p. 93)

Isso significa que, nesse contexto, utiliza-se, equivocadamente, o termo "avaliação", porque, em último 
termo, considera-se e pratica-se a mensuração e a verificação da aprendizagem. Conforme indicado por Worthern and Sanders (1973), a avaliação não é um conceito novo; e, tendo em vista a sua definição ampla como "a determinação do valor de ..." ou "a valoração de ... ", pode-se argumentar que a avaliação tem sempre acompanhado as pessoas e que cada uma delas, de seu próprio modo, é um avaliador. Porém, a "determinação do valor de ..." pode se referir à utilidade de alguma coisa para cumprir determinada tarefa ou para servir a determinado propósito, sem necessariamente estar relacionada com o seu "valor", entendido "valor" em termos de qualificação de um objeto relativamente a um critério preestabelecido, cientificamente e/ou socio-culturalmente entendido e aceito como válido para valorar aquele objeto. Na medida em que é através da mensuração que se processa a coleta de informações relevantes para caracterizar um objeto qualquer, então a mensuração está a serviço da valoração desse objeto relativamente a critério(s) pertinente(s), do julgamento de valor do objeto, ou da avaliação do objeto. Portanto, se fosse o caso, a avaliação não poderia ser entendida como ou confundida com a mensuração; e, se a mensuração fosse entendida como ou confundida com a avaliação, isso somente poderia ocorrer enquanto se entendendo valoração em termos de "utilidade para ...".

Subjacentes ao referido modo convencional, normativo, do "fazer pedagógico", pode-se identificar, principalmente, as seguintes suposições básicas e características (Mildner, 1996; Governo do Estado de Pernambuco, 1996a):

$>$ em um grupo de indivíduos cuja amplitude de faixa etária é de 12 meses, todos eles se encontram em um mesmo estágio de desenvolvimento e, portanto, hão de 
aprender os mesmos conteúdos, do mesmo modo, no mesmo dia, em um mesmo tempo de estudo;

$>$ a meta da educação formal é o desenvolvimento intelectual;

> a organização mais efetiva é a divisão do currículo escolar em disciplinas, habilidades e conteúdos prédeterminados supostamente adequados às diferentes idades cronológicas;

> desenvolvimento cognitivo, a aprendizagem, o rendimento, o aproveitamento escolar estão diretamente relacionados à idade cronológica dos alunos;

$>$ o desenvolvimento da aprendizagem com sucesso constitui uma variável dependente apenas de níveis específicos de desenvolvimento cognitivo, os quais estão fortemente associados à idade cronológica e, também, da eficácia de dada prática pedagógica em si mesma, ignorando as diferenças e necessidades individuais de desenvolvimento e aprendizagem;

> o planejamento do processo de ensino-aprendizagem é realizado apenas pelo professor, de acordo com suas preferências e conhecimentos atuais, contemplando conteúdos do saber escolar de modo atomístico e fragmentado, bem como - metodologias de ensino consideradas adequadas "para todos os alunos";

$>$ o processo de ensino-aprendizagem é realizado sem a necessária relação de reciprocidade e dependência entre o ensino e a aprendizagem, fundamentado na transmissão-recepção de conhecimentos usualmente acumulados pelo próprio professor e em seus próprios termos, de acordo com a linguagem característica de seu ambiente e bagagem sociocultural; 
$>$ a qualidade das aprendizagens realizadas pelos alunos e de seus correspondentes desempenhos é preterida, predominando a preocupação com a quantidade de informações relacionadas com o saber sistematizado que são "repassadas" tais como existentes na bagagem do professor;

> coerentemente, a mensuração e a verificação dos desempenhos de aprendizagem manifestados pelos alunos concentram-se em situações específicas de testagem de habilidades de memorização mecânica de conceitos e procedimentos, sendo raramente contemplados patamares mais complexos de competências no trato do conhecimento; tais mensuração e verificação de desempenhos de aprendizagem são periódicas e terminais, visando a classificar os alunos, aprová-los ou reprová-los;

> assim, não se realiza, em último termo, avaliação da aprendizagem, a qual, a partir da mensuração e da verificação, implica, necessariamente, em julgamento de valor e elaboração de alternativas de decisão sobre procedimentos de ensino-aprendizagem que oportunizem a realização efetiva de aprendizagens ainda não processadas e fomentem aquelas em processamento (Hoffman, 1994; Luckesi, 1995, Sousa, 1995b).

Ora, de acordo com Mildner $(1980,1999)$ esse tipo de processo pedagógico, e não somente o tipo de mensuração/ verificação de aprendizagem (equivocadamente denominado "avaliação") que é processado, finda por estabelecer os alunos que, por suas características individuais, mais ou menos compatíveis ao tipo de metodologia de ensino adotado e às características e mazelas do professor, são fadados ao "sucesso" 
ou ao "fracasso". Isso significa, em último termo, a concretização de seleção discriminatória de indivíduos considerados, tão somente, "talentos naturais", ou pelo menos, "naturalmente mais talentosos" - entenda-se: talentos naturais para mais correta capacidade de ajustamento às metodologias de ensino-aprendizagem padronizadas, oferecidas para todos, pelo professor. Em outras palavras, trata-se de um processo pedagógico que em sua totalidade - considerado tanto o planejamento, quanto o processo de ensino-aprendizagem, como a "avaliação" da aprendizagem - mantém os alunos consistentes e estáveis ao longo do tempo, quer como pessoas quer como alunos, em seus diferenciados e "perpetuados" níveis de consecução de aprendizagens, "perpetuados" desde que aceitos como dados e nunca objeto de otimização. Portanto, é desse modo que, no bojo do processo pedagógico, a "avaliação da aprendizagem" que se diz processar nesse contexto educacional, não propriamente produz, mas apenas explicita, em suas últimas conseqüências, um viciado processo seletivodiscriminativo daqueles alunos "talentos naturais" ou "naturalmente mais talentosos", e simultaneamente a progressiva caracterização do contingente de alunos cronicamente "abaixo da média", o que induz a sua eventual marginalização ou mesmo eliminação, a curto ou a mais longo prazo (Mildner, 1980, 1999).

Com base em Luckesi (1995), pode-se dizer que esse modo de "fazer educação" reflete o modelo liberal conservador da sociedade, cujo objetivo é conservá-la na sua configuração, e por isso, implícita ou explicitamente, desse ou daquele modo e nessa ou naquela extensão, propõe e pratica a adaptação e o enquadramento dos educandos no modelo social dominante.

Portanto, o processo pedagógico conservador tradicional caracteriza-se por um planejamento e exercício de 
ensino - aprendizagem autoritários, seletivos - classificatórios - discriminativos, e, consequentemente, por planejamento e exercício de avaliação da aprendizagem correspondentemente adequados, porque revestidos dessas mesmas características.

\section{A avaliação da aprendizagem e sua função na melhoria da qualidade do ensino-aprendizagem}

Conforme indicado anteriormente, no contexto tradicional da educação não se processa a "avaliação da aprendizagem" em seu sentido e significado estritos, e, os mecanismos através dos quais, nesses sentido e significado, ela poderá ser realizada, nomeadamente, a mensuração e a verificação da aprendizagem, são essencialmente classificatórios e são seletivosdiscriminativos porque situados e utilizados no bojo de um processo pedagógico dotado dessas mesmas características.

Com efeito,

"A avaliação da aprendizagem escolar adquire seu sentido na medida em que se articula com um projeto pedagógico e com seu conseqüente projeto de ensino. A avaliação, tanto no geral quanto no caso específico da aprendizagem, não possui uma finalidade em si; ela subsidia um curso de ação que visa construir um resultado previamente definido." (Luckesi, 1995, p. 85)

Nesse mesmo sentido, Mildner (1996) indica que sendo a prática de avaliação da aprendizagem o reflexo da ideologia subjacente à prática do planejamento e do processo de ensinoaprendizagem, bem como os correspondentes princípios e metodologias, segue-se, naturalmente, que a referida prática de avaliação não é a causa dos resultados que verifica, nem mesmo da interpretação a eles dada ("fracasso" ou "sucesso"). Ou seja, esses resultados, seu entendimento, e, na verdade, a própria 
verificação dos desempenhos de aprendizagem, são, em último termo, conseqüência dos princípios, dos propósitos e conteúdos, estratégias, métodos e técnicas que permeiam o processo de ensino-aprendizagem no dia-a-dia da educação escolar. Desse modo, se a avaliação escolar, tradicionalmente em prática, reveste-se do caráter seletivo-classificatório que fortalece o "fracasso" escolar, ela assim se processa porque adequadamente coerente com os princípios, propósitos e "o fazer" da prática pedagógica vigente. Nessa perspectiva, a minimização do fracasso escolar e a realização efetiva de uma educação de qualidade para todos não decorrerá primeira e principalmente de uma "mudança de cultura avaliativa", e sim demandará mais básica e abrangente mudança de cultura pedagógica.

Pode-se inclusive dizer que a prática da avaliação da aprendizagem, numa perspectiva de educação para a transformação social, dissociada da prática do planejamento e do processamento do ensino e da aprendizagem nessa mesma perspectiva, findará por conduzir" ... à progressiva caracterização do contingente de alunos cronicamente "abaixo da média" e à sua eventual marginalização ou mesmo eliminação; assim, embora a mais longo prazo e de modo menos explícito, por quasi-espontâneo, ao mesmo processo de seleção discriminatória para sucesso de estudantes 'talentos naturais' ..." (Mildner, 1980, p. 16), tal como promovido pela prática convencional, seletivo-discriminativa, terminal, sentenciva da avaliação, hoje, nas escolas.

Paralelamente, identifica-se, na literatura sobre avaliação da aprendizagem, principalmente no Brasil, desde o final da década de 1970, uma certa tendência de, no nível político e metodológico, configurar a avaliação de desempenhos escolares como o elemento preponderante, e, por vezes, até 
mesmo exclusivo para a superação da questão do fracasso escolar, manifestada nos altos índices de reprovação, repetência e evasão, bem como para a promoção de uma educação de qualidade para todos. Este período revestiu-se de posturas críticas acerca da educação em geral, e da escola em particular, em termos de características reprodutoras de uma ideologia dominante, das relações de poder e de dominação, incluindo em seu âmago a especificação da avaliação enquanto uma prática pedagógica voltada para a reprodução da estrutura sócio-econômica dominante (Sousa Zakia, 1993). A partir de uma primeira denúncia explícita da avaliação da aprendizagem como "... um dos mais eficazes instrumentos de controle da oferta e do aproveitamento de oportunidades educacionais e sociais e de dissimulação de um processo de seleção em que, sob uma aparente neutralidade e equidade, a alguns são oferecidas sucessivas oportunidades educacionais $e_{1}$ em conseqüência, oportunidades sociais, enquanto a outros essas oportunidades são negadas, processo que se desenvolve segundo critérios que transcendem os fins declarados da avaliação" (Soares, 1978), seguiu-se um movimento nacional de denúncia individual e coletiva dessa função reprodutora da avaliação exercida no dia-a-dia escolar, permeado de propostas, no nível conceitual, do que há de ser a avaliação da aprendizagem democrática, transformadora.

Conforme indicado em Sousa (1998), a análise e a denúncia da função política da avaliação, foi objeto de estudo de avaliadores brasileiros, como, por exemplo, Ana Maria Saul, Carlos Cipriano Luckesi, Magda Becker Soares, Sandra Zakia Lian de Souza, Pedro Demo, Jussara Hoffman, Celso dos S. Vasconcelos, Mere Abramovich, Lea Depresbiteris, Maria Laura Barbosa Franco, Menga Lüdke, Thereza Penna Firme, os quais buscaram, também, "... construir uma nova teoria de avaliação 
que pudesse produzir modificações de práticas para superar no cotidiano escolar as indignidades já exaustivamente denunciadas." (p. 165)

Talvez esse movimento, que persiste até hoje, tenha se concentrado excessivamente sobre a avaliação em si mesma e por si mesma, tendendo a manifestar sua superestimação como o mecanismo precipuamente responsável pelas desigualdades educacionais em todos os sentidos, e concomitantemente, como o mecanismo primeiro pelo qual essas desigualdades haverão de ser solucionadas, daí resultando um possível viés conceitual acerca do fato de que planejamento, processamento e avaliação da aprendizagem são elementos constituintes do processo pedagógico, os quais interagem em seus efeitos simultâneos e integrados, através de íntimas relações de reciprocidade e de complementariedade, sobre e para a ocorrência efetiva da aprendizagem para todos. E/ou a expectativa de que, modificado o processamento da avaliação da aprendizagem, resulte alterado para melhor o quadro geral do "fracasso" escolar, numa perspectiva que centra a avaliação como o mecanismo precípuo, através do qual se manifestam, por seus resultados, tanto as deficiências do processo de ensino-aprendizagem, quanto a formalização do "fracasso" desse processo, ao qual, uma vez declarado, segue-se a consumação de suas conseqüências institucionais: reprovação e repetência; e por força desta: evasão.

Em outras palavras, dispõe-se de uma considerável literatura acadêmica sobre avaliação da aprendizagem, que não aborda, pelo menos explicitamente, o planejamento e o processamento do ensino-aprendizagem como práticas pedagógicas necessárias para, e intimamente articuladas com a implementação, em sua inteireza, da avaliação transformadora, de encaminhamentos democráticos. $\mathrm{Na}$ 
verdade, trata-se de uma literatura que implicitamente reconhece a ação e influência direta da avaliação sobre o planejamento, o ensino e a aprendizagem na escola e é explicitamente indicativo dessas ação e influência (p. ex., Vasconcelos, 1993). Em alguns casos; também alerta para o fato de que em sendo a avaliação meio e não fim em si mesma, ela se delimita e é dimensionada pela teoria e pela prática pedagógicas que a circunstancializam (Luckesi, 1995; Sousa, 1995,1998). Porém, mais uma vez, o tratamento que é dado à avaliação, seja abordando-a em suas características reprodutoras das condições sociais, seja enfocando-a em sua função transformadora, não se estende, articuladamente ou não, aos demais elementos do processo pedagógico que a delimitam e dimensionam em suas natureza, função e operacionalização.

Talvez isso tenha origem numa tentativa de evitar um explícito retorno a uma relativa abordagem tecnicista do processo pedagógico em seu todo e nas práticas que o compõem, mesmo reconhecendo a reciprocidade das dimensões política, técnica e humana da prática pedagógica e a íntima e imprescindível articulação entre essas dimensões (Candau, 1996; Lelis, 1995; Paulo, 1995, dentre outros). De todo modo, trata-se de um procedimento que finda por "tricotomizar", no plano conceitual, pelo menos para o leitoraprendiz da avaliação educacional em geral e da avaliação da aprendizagem em particular, desta ou daquela maneira e nesta ou naquela extensão, os componentes fundamentais do processo pedagógico - o planejamento, a implementação do processo de ensino-aprendizagem e a avaliação da aprendizagem.

É nesse sentido que cabe e cumpre aqui apresentar as citações que seguem. 
Segundo Soares (1978),

Implicitamente e mascaradamente, a avaliação exerce $o$ controle do conhecimento $e_{\text {, }}$ dissimuladamente, o controle das hierarquias sociais.

A avaliação exerce o controle do conhecimento na medida em que define o que deve saber o estudante e avalia se ele sabe tudo o que deve saber e apenas o que deve saber, e ainda se sabe tal como deve saber. .... Medindo, na verdade, (grifos nossos) os resultados do processo de socialização, a avaliação declara estar medindo o mérito, e atribui a responsabilidade dos resultados obtidos aos atributos do estudante ... ou aos atributos do professor ..

... as funções sociais que a avaliação desempenha no sistema educacional estão permanentemente presentes no processo de ensino.

Estão presentes nos mecanismos de seleção em que, ostensivamente e sob a aparência de uma absoluta neutralidade, alguns são escolhidos e muitos são rejeitados por um processo de eliminação cuja relação com a hierarquia social é dissimulada por sua pretensa objetividade....

... a avaliação, sob uma falsa aparência de neutralidade e de objetividade, é o instrumento por excelência de que lança mão o sistema de ensino para o controle das oportunidades educacionais $e$ para dissimulação das desigualdades sociais, que ela oculta sob a fantasia do dom natural e do mérito individualmente conquistado. (pp. 47-53)

\section{Vasconcelos (1995) denuncia que}

A avaliação escolar não tem sido apenas avaliação. Do ponto de vista do sistema, representa uma forma de inculcação ideológica e seleção social; para os professores, muitas vezes, representa uma forma de controle de "julgamento" da pessoa do educando; para os pais, significa o "passaporte" para a ascensão social ... A finalidade da avaliação, dentro de um 
horizonte de uma educação libertadora, numa abordagem sócio-interacionista, é ajudar a escola a cumprir sua função social transformadora, ou seja, favorecer que os alunos possam aprender mais $e$ melhor, tendo em vista o compromisso com uma sociedade mais justa e melhor .... O que se espera é que através da avaliação o professor possa ter elementos para ver qual o melhor caminho para ensinar, como os alunos aprendem melhor. Estar avaliando para ver se o tipo de trabalho que está fazendo está de fato atingindo os alunos. Se o professor usa a avaliação desse modo, terá elementos para melhorar sua forma de ensinar .... A avaliação deve servir para isto: para que o professor capte as necessidades do aluno em termos de aprendizagem, e/ou as suas necessidades em termos de ensino (além, é claro das outras necessidades relacionadas à escola, sistema de ensino, sociedade). Para a concretização da mudança da avaliação, para colocá-la no seu devido lugar, qual seja, como um meio e não como um fim - da forma como vem ocorrendo - precisamos de práticas concretas [de avaliação] que incorporem estes novos princípios .... Quando o sujeito é avaliado de uma forma que o respeite e quando sabe que o resultado da avaliação não vai se voltar contra ele, mas a favor dele, fica tudo muito mais natural. Este é o desafio que está colocado aos professores que buscam uma nova prática pedagógica. (pp. 87-89)

\section{Sousa (1998) expressa que}

... a avaliação deve ajudar o professor a identificar onde estão os problemas de aprendizagem, para que possamos aperfeiçoar o ensino .... $O$ grande problema que acho que enfrentamos não é evidentemente o como avaliar, mas sim o como ensinar. Quanto mais apuro meus procedimentos de avaliação, mais consigo desenvolver hipóteses sobre 
dificuldades dos alunos, processos de ensino, modelos de aprendizagem e aspectos que devo aperfeiçoar em minha formação de professora ... avaliar exige um profundo estudo sobre aprendizagens e uma postura política comprometida com o processo de transformação social. A grande questão então que se coloca para nós professores, hoje, não é como avaliar mas sim por que o aluno não está aprendendo. Por que determinado aluno vai bem e outro não? Qual método foi mais adequado nesta classe? Quais procedimentos têm promovido melhores aprendizagens? .... Nosso problema é justamente como identificar, analisar o processo de aprendizagem do aluno e oferecer um ensino de qualidade. (pp. 170-1)

Luckesi (1995) refere-se à sua proposição de "avaliação diagnóstica", desenvolvida em 1984, "... como uma saída para o modo autoritário de agir na prática educativa em avaliação, e como meio de auxiliar a construção de uma educação que estivesse a favor da democratização da sociedade." (p. 11), enquanto enfaticamente afirma que

Seria um contra-senso que um modelo social e um modelo pedagógico autoritários e conservadores tivessem no seu âmago uma prática de avaliação democrática. .... o educador que estiver afeito a dar um novo encaminhamento para a prática da avaliação escolar deverá estar preocupado em redefinir ou em definir propriamente os rumos de sua ação pedagógica ... o primeiro passo que nos parece fundamental para redirecionar os caminhos da prática da avaliação é assumir um posicionamento pedagógico claro e explícito ... de tal modo que possa orientar diuturnamente a prática pedagógica, no planejamento, na execução e na avaliação. (Luckesi, 1995, p. 42) 
Exatamente nesse sentido, e visando uma tentativa de superação da referida provável "tricotomia" geralmente identificada, ou pelo menos inconscientemente consentida e mais ou menos explicitamente teorizada, entre as referidas três práticas pedagógicas constituintes do processo pedagógico formal: o planejamento e o processo de ensino-aprendizagem e o processo de avaliação da aprendizagem, reafirma-se que qualquer proposta de modificação da prática vigente de avaliação educacional deve concomitante e necessariamente, incluir propostas coerentemente pertinentes de modificação das práticas atuais de planejamento e de processo de ensinoaprendizagem. Tudo isso centrar-se-ia em torno da compreensão de que a discussão e proposição metodológica de "como fazer a educação" deve processar-se em harmônica e efetiva articulação de todos os aspectos envolvidos neste "como fazer", e deles com "o para que fazer e o que fazer pedagógico" (Luckesi, 1996; Paulo, 1995; entre outros).

Exatamente nessa perspectiva, tenta-se, a seguir, contrapor um tipo de processo pedagógico cujo objetivo precípuo seja a melhoria da qualidade da educação para todos, numa perspectiva de transformação, e não reprodução social, e que se detenha, com igual ou equilibrada ênfase, naquelas três práticas pedagógicas, não em termos de suas relativas autonomias, mas necessariamente na relação de reciprocidade e complementaridade entre elas (Vasconcelos, 1995; Paulo, 1995; Mello, 1979; Mildner, 1996, entre outros).

\section{A avaliação da aprendizagem numa perspectiva de educação transformadora}

Tal como anteriormente indicado, numa perspectiva de educação transformadora, ao invés de educação liberalconservadora, o ponto crucial configura-se como sendo o 
desenvolvimento e implementação de um sistema educacional comprometido com a transformação social. De acordo com Mildner (1980, 1996), isso implica, necessariamente, na conceituação e práticas explícitas de um processo pedagógico cujos princípios, propósitos e elementos constituintes sejam coerentes em seus inteirezas, e convirjam sincronicamente tanto para a superação da evasão escolar quanto para a desmistificação da relação entre nível sócio-econômico, desempenho e rendimento escolar, no sentido da concretização de uma correta otimização da qualidade da educação para todos, ou pelo menos para a maioria dos alunos. Trata-se aqui, precipuamente, da otimização do ensino-aprendizagem para cada estudante individualmente, no sentido de máximos desempenhos e rendimentos de aprendizagem, ou de máxima efetividade na obtenção de domínios de aprendizagens diversas, a níveis mínimos desejáveis e necessários para o desenvolvimento e formação integrais da personalidade e para a continuidade de realização de aprendizagens mais complexas, críticas e criativas. Por sua vez, tal otimização imprescinde de um processo pedagógico no qual a construção/re-construção de um novo, modificado ou renovador saber, é realizada indiscriminadamente por todos os alunos, considerados estes em suas atuais bagagens culturais e sócio-econômicas. Isso demanda um processo de mudança de concepções e de práticas de planejamento, de ensino, de aprendizagem - e consequentemente de avaliação -, simultaneamente considerados em suas adequadas articulações, no contexto da educação escolar pretendida. (Mildner, 1980, 1996).

Desse modo, a dimensão da prática docente, considerada em todos os seus componentes, "... representa um ângulo da dimensão política, na medida em que a busca de formas que favoreçam a aquisição do saber, por uma parcela cada vez mais 
expressiva das classes subalternas, faz parte do compromisso com a sua libertação" (Paulo, 1996).

Agora, as suposições básicas que norteiam o desenvolvimento e a prática de processo pedagógico coerente com uma concepção de educação para transformação, ou, operacionalmente, de educação de qualidade para todos, fundam-se em princípios e evidências advindas de pesquisas sobre desenvolvimento humano que, traduzidos para o plano da melhoria da qualidade do ensino, podem ser entendidos como a seguir, conforme indicado em Bender (1980) e em Governo do Estado de Pernambuco (1996a, 1998):

> os alunos diferem em seus atuais níveis cognitivo, social, emocional e físico. Assim, em vez de progredir em um ritmo fixo, cada um, alternadamente, avança com sucesso, rapidamente ou mais vagarosamente, porém de forma progressiva, em diferentes contextos de ensino e de aprendizagem, considerados os diversos conteúdos, habilidades, estratégias e métodos;

$>$ diferenças individuais em graus e níveis de desenvolvimento intelectual, social, emocional e físico, que se relacionam com resultados de aprendizagem, devem ser consideradas como diferentes susceptibilidades individuais a diferentes contextos de ensino e de aprendizagem;

$>$ o contexto de ensino e de aprendizagem adequado a um determinado tipo de aluno, com determinado ritmo de desenvolvimento-aprendizagem e com determinadas configurações particulares atuais de habilidades cognitivas, de fatores emocionais e de background social, não necessariamente será adequado para outro tipo de aluno, não importando quanto, "em 
média", esse contexto seja mais eficaz do que qualquer outro;

$>$ toda e qualquer prática pedagógica deve objetivar, não só o desenvolvimento intelectual de cada indivíduo, mas também, paralelamente e com a mesma intensidade e intencionalidade, o respectivo desenvolvimento social e emocional, fomentando, assim, o auto-respeito, a independência, a autoconfiança, a auto-motivação, os métodos e meios próprios de socialização construtiva permeada pela colaboração e pela cooperação;

$>$ diferenças e necessidades individuais de desenvolvimento devem ser levadas em conta para identificar contextos particulares de ensino e de aprendizagem que as atendam adequadamente, de modo a fomentar o desenvolvimento global do indivíduo;

$>$ uma real e concreta melhoria da qualidade do ensino e da aprendizagem exige a adoção de diversidades de contextos de ensino e de aprendizagem, e o instigar dos pertinentes desenvolvimentos cognitivo, social e físico;

> os processos de ensino e de aprendizagem, na escola, podem ser entendidos enquanto movimento interativo, no qual, a atividade intelectual do aluno se dá pela reflexão de conteúdos específicos de ensino, em situações problematizadoras e coletivas;

> são relevantes os conhecimentos prévios dos alunos constituídos em sua comunidade sociocultural;

$>$ há relações entre conhecimentos prévios e novos conhecimentos a serem construídos; 
> a significação da aprendizagem está diretamente vinculada à sua aplicabilidade;

> há necessidade de conflito/problematização como procedimento pedagógico nos processos de ensino e de aprendizagem;

> a aprendizagem se dá de forma progressiva e gradual, exigindo uma organização curricular coerente;

> a aprendizagem é definitivamente dependente do processo de descoberta, pelo aluno, da existência de idéias diferentes das suas;

Parece, pois, que um processo pedagógico voltado para a transformação social e educacional deve, em termos operacionais, incluir, primeira e necessariamente, pelo menos quatro aspectos fundamentais, entre outros:

> Planejamento aberto-dinâmico do processo de ensinoaprendizagem, e, nestes termos, processado, contínua, cumulativa, e sistematicamente, em função das realidades concretas dos alunos evidenciadas através das respectivas diferenças individuais (características e necessidades) refletidas em seus atuais conhecimentos e modos de processar os conteúdos do saber escolar, e em modos diversos de ensino que possibilitem reais condições de construção/re-construção dos conhecimentos socio-historicamente produzidos.

- Abordagem sócio-crítica dos conteúdos do saber escolar, através do reconhecimento e exploração, conscientes e concretos, dos conhecimentos prévios de todos os alunos, bem como de seu mundo social e cultural, de suas percepções, motivações, práticas de vida, linguagem, no sentido da construção/reconstrução, por cada um deles, dos conteúdos do saber escolar: "O ensino contribui para a superação do 
fracasso escolar se os objetivos e conteúdos são acessíveis, socialmente significativos e assumidos pelos alunos, isto é, capazes de suscitar sua atividade e suas capacidades mentais, seu raciocínio, para que assimilem consciente e ativamente os conhecimentos" (Libâneo, 1994, p. 43).

> Diversificação e compatível participação de alunos em metodologias de ensino-aprendizagem que lhes sejam os mais adequados, sem a ninguém marginalizar, ou eliminar, direta ou indiretamente: a abordagem metodológica de ensino-aprendizagem que for a melhor para determinado tipo de estudante, com determinadas configurações particulares de características e necessidades de desenvolvimentoaprendizagem, não será também a melhor para outro tipo de estudante, com outras determinadas configurações particulares de características e necessidades de desenvolvimento-aprendizagem, envolvidos esses diferentes tipos de estudantes e vários outros (Mildner, 1980). "É necessário que as escolas tenham identidade como instituições de jovens e que essa identidade seja diversificada em função das características do meio social e da clientela. Diversidade, no entanto, não se confunde com fragmentação, muito ao contrário. Inspirada na política da igualdade, a diversidade reconhece que a eqüidade se alcança pela igualdade de oportunidade com diversidade de tratamento. Dessa forma a diversidade ... é necessária para contemplar as diferenças nos pontos de partida de seu alunado, exatamente por ser essa a forma mais eficaz de garantir a todos um patamar comum no ponto 
de chegada." (Ministério da Educação e do Desporto, junho 1998, p. 30)

> Respeito ao ritmo próprio de desenvolvimentoaprendizagem de cada um e de todos os alunos. Diferenças em ritmos de desenvolvimentoaprendizagem não significam diferenças nas respectivas "capacidades" de construção/re-construção autônoma do conhecimento social e historicamente acumulado que são abordados enquanto conteúdos do saber escolar. Essas diferenças refletem, mais propriamente, diferentes modos de processar o pensamento e o raciocínio nos diversos patamares atuais de competências e habilidades sociais e psicopedagógicas: O ritmo de desenvolvimento-aprendizagem do aluno "... é alusivo ao desenvolvimento cognitivo que se dá por processo de interação social ... Esse tempo particular e singular é diverso, sendo ele a base da heterogeneidade dos ritmos $e$ dos modos de apropriação do conhecimento." (Governo do Estado de Pernambuco, 1998, p. 15)

Desse modo entendidos esses aspectos pedagógicos, eles implicam no trato adequado da questão de igualdade de oportunidades de ensino-aprendizagem com qualidade para todos. Aqui, igualdade de oportunidades de ensinoaprendizagem se traduz em termos de propiciação de diversidade de tratamentos de ensino-aprendizagem sempre que os alunos dela necessitarem e respeito aos respectivos ritmos individuais de desenvolvimento-aprendizagem, independentemente do tempo pedagógico convencional firmado, a fim de que todos alcancem os patamares de conhecimento desejados e necessários para uma possível transformação do "status quo" social. 
Paralelamente, essa configuração de pedagogia renovadora, permeada de encaminhamentos democráticos, há ainda de ser complementada, necessariamente, por um tratamento adequadamente coerente de avaliação da aprendizagem, a qual deverá estar comprometida com sucesso e progresso para todos os alunos. Agora, a avaliação da aprendizagem é entendida como

" ... um juízo de qualidade sobre dados relevantes, tendo em vista uma tomada de decisão .... o juízo de qualidade é produzido por um processo comparativo entre o objeto que está sendo ajuizado e um determinado padrão ideal de julgamento .... refere-se ... ao aspecto adjetivo, qualitativo do objeto. .... na avaliação da aprendizagem ... há um dado de realidade, que são as condutas dos alunos, e há uma atribuição de qualidade a essa realidade a partir de um determinado padrão ideal dessa conduta. Ou seja, o professor, tendo em suas mãos os resultados da aprendizagem do aluno, compara esses resultados com a expectativa de resultado que possui (padrão ideal de julgamento) e atribui-lhe uma qualidade de satisfatoriedade ou insatisfatoriedade .... [que] subsidia o reencaminhamento da ação, possibilitando consequências no sentido da construção dos resultados que se deseja" (Luckesi, 1995, pp.69-94)

Sousa (1995b) afirma que:

Verificar se objetivos [de ensino-aprendizagem] estão ou não estão sendo atingidos descrevendo como, por quê e de que tipo são as dificuldades e facilidades do aluno não encerra, no entanto, a função avaliativa. Sendo seu compromisso fundamental a melhoria do ensino e a garantia da aquisição de aprendizagens, cumpre-lhe, como papel, analisar e propor as revisões e encaminhamentos necessários para que os 
objetivos sejam atingidos. Assim sendo, seu processo final culmina não na aprovação ou reprovação mas em prescrições pedagógicas que possam tornar o ensino mais efetivo.

É portanto, uma prática pedagógica que atende às necessidades do educador para indicar-lhe caminhos, refletir sua ação entre os alunos (p. 143-4)

Hoffman (1994) propõe uma ação avaliativa mediadora que

... envolveria um complexo de processos educativos que se desenvolveriam a partir da análise das hipóteses formuladas pelo educando, de suas ações e manifestações .... Torna-se, então, sumamente importante o acompanhamento pelo professor das tarefas realizadas pelo educando ... Só que esse 'acompanhar' abandona o significado atual de retificar, reescrever, sublinhar, apontar erros $e$ acertos. E se transforma numa atividade de pesquisa e reflexão sobre as soluções apresentadas pelo aluno ... Dessa forma, o processo avaliativo ... é um método investigativo e que prescinde da correção tradicional, impositiva e coerciva. Pressupõe, isso sim, que o professor esteja cada vez mais alerta e se debruce compreensivamente sobre todas as manifestações do educando. O erro lido em sua lógica, as hipóteses preliminarmente construídas pelo aluno (o "ainda não, mas pode ser") são elementos dinamizadores da ação avaliativa ... (pp. 72-9)

Luckesi (1995) parece propor que introduzir a prática da avaliação da aprendizagem em seus mais verdadeiros significado e natureza, implica concebê-la e praticá-la como "... o instrumento do reconhecimento dos caminhos percorridos e da identificação dos caminhos a serem perseguidos .... como um mecanismo de compreensão do estágio de aprendizagem em que se encontra o aluno, tendo em vista tomar decisões suficientes e 
satisfatórias para que possa avançar no seu processo de aprendizagem ... [a fim de] poder trabalhar com ele para que saia do estágio defasado em que se encontra e possa avançar em termos dos conhecimentos necessários" (Luckesi, 1995, pp. 43, 81-2).

Esses posicionamentos acerca da essência da avaliação da aprendizagem resgatam os princípios e a concepção originais da avaliação educacional, centrada em julgamento de valor e tomada de decisão, no espírito da avaliação formativa.

Conforme enfocada na literatura pertinente, a avaliação formativa, tendo como objeto alunos, programas, projetos, estratégias e instrumentos de ensino e de aprendizagem, e inclusive instituições, é entendida e é processada como contínuo e sistemático processo de descrição de objetos sócioeducacionais e de julgamento de seus méritos (relativamente a outros objetos funcionalmente semelhantes) e seus valores (com referência a eles próprios), manifestados esses na concepção e prática do fazer pedagógico. Assim, visa a avaliação formativa fornecer, regularmente, dados avaliativos que sirvam de bases concretas para tomadas de decisão incidentes sobre a melhoria e o aperfeiçoamento constantes daqueles objetos (Nevo, 1983; Lewy, 1988; Stufflebeam, 1971; Scriven, 1967, Cronbach, 1957; entre outros).

Aplicada essa concepção de avaliação no contexto do processo pedagógico, diz-se que ela tem por propósito a melhoria e o aperfeiçoamento do ensino, da aprendizagem e de seus respectivos conseqüentes desempenhos e rendimentos. Ou seja, a avaliação formativa da aprendizagem é um dos componentes do processo pedagógico e, incidindo diretamente sobre o planejamento, a prática e os produtos de ensinoaprendizagem, se configura em uma estratégia de verificação da 
qualidade desse ensino e dessa aprendizagem, em seus méritos e em seus valores, a qual, por sua vez, em seus resultados, deve, necessariamente, sugerir alternativas de procedimentos que conduzam à melhoria daquela qualidade observada (Mildner, 1996).

Com base em Luckesi (1995), pode-se dizer que a avaliação formativa ${ }^{2}$ é o instrumento dialético do avanço, o instrumento da identificação de novos rumos. Enfim, "... o instrumento do recoconhecimento dos caminhos percorridos e da identificação dos caminhos a serem perseguidos." (p. 43).

Desse modo e nessa perspectiva, a avaliação da aprendizagem será entendida e será processada, ao longo da realização dos processos de planejamento e de ensinoaprendizagem, de forma contínua, cumulativa e sistemática, cujos objetos serão, simultaneamente, as aprendizagens e o

2 Cumpre notar que Luckesi (1995), Sousa (1995b), Vasconcelos (1995), entre outros, referem-se a essa concepção de avaliação como sendo avaliação diagnóstica. Do que se percebe nessas referências, conforme notado por Mildner (1996), a chamada avaliação diagnóstica tenta, em último termo, retomar a função formativa da avaliação educacional. Deste modo, seria então a abordagem de avaliação formativa que concretamente os referidos autores têm em vista. Segue-se, desde já, que a avaliação diagnóstica não se apresenta como um novo paradigma, mas como alteração de denominação da existente abordagem de avaliação formativa. Mildner (1996), observa, também, que o conceito "diagnóstico" não é corretamente adequado àquela tentativa de apropriação do significado da função formativa da avaliação. Por "diagnóstico" se entende a constatação, e somente a constatação, de um determinado estado ou situação. Portanto, uma avaliação diagnóstica não implicaria a indicação de modos de aperfeiçoamento do processo de ensino-aprendizagem. Seus resultados poderão simplesmente denunciar níveis de consecução da aprendizagem pelos alunos. 
ensino, no sentido de desenvolvimento e crescimento, autoconhecimento, auto-respeito, ao invés de autoritarismo e punição. $E$, portanto, de modo adequadamente coerente com os princípios e evidências, bem como com os demais aspectos anteriormente referidos como pertinentes a uma pedagogia para educação de qualidade para todos. Enfim, a realização da avaliação formativa encontra seu sentido no bojo da pedagogia transformadora, democrática, constituindo-se num momento dialético do processo de avançar no desenvolvimento da ação, do crescimento para a autonomia, do crescimento para a competência, um momento dialético de "senso" do estágio em que se está e de sua distância em relação à perspectiva que está colocada como ponto a ser atingido, incluída a obrigatoriedade da tomada de decisão quanto à ação para desenvolvimento, crescimento, quando ela está avaliando uma ação (Luckesi, 1995, 1996)

Pode-se ainda dizer, de acordo com Mildner (1996), que a avaliação, nesse espírito de abordagem formativa, inclui os conceitos e a realização de diagnóstico e de interação, com base nos quais serão indicadas alternativas de tomadas de decisão para a melhoria da qualidade do processo pedagógico. Pelo "diagnóstico", ela denuncia níveis de consecução da aprendizagem pelos alunos. Por "interação" se entende o contato direto de um objeto com outro e seu mútuo entrelaçamento. Esse sentido de interação manifesta-se na avaliação formativa porque ela terá de se processar junto a cada aluno individualmente, a fim de identificar concretamente suas próprias razões para esses ou aqueles tipos de desempenhos no decorrer do processo de ensino-aprendizagem, desempenhos esses que são previamente delimitados como desejáveis e necessários. Nessa perspectiva pode-se dizer que a avaliação ou, mais especificamente, a avaliação formativa deve ser 
processada participativamente por professores e alunos: os dados coletados através dos seus instrumentos de mensuraçãoverificação dos desempenhos de aprendizagem devem servir de base para uma compreensão adequada do processo desenvolvido pelos alunos, e com eles discutidos a fim de que "... professor e alunos cheguem juntos a um entendimento da situação de aprendizagem que, por sua vez, está articulado com o processo de ensino." (Luckesi, 1995, p. 84) Segundo Hoffman (1994), a avaliação da aprendizagem é um processo interativo, através do qual educandos e educadores aprendem sobre si mesmos e sobre a realidade escolar. Conforme posto em Governo do Estado de Pernambuco (1998), "... uma avaliação de qualidade não põe seus sujeitos 'para trás', ao contrário, compromete-se com o avanço, investindo nas suas possibilidades, elevando suas expectativas, ampliando e preservando a autoestima, instigando-os à curiosidade e à descoberta. Ampliar sempre as possibilidades de aprendizagens para os alunos e jamais subtraí-las" (p. 27) De acordo com Vasconcelos (1995), "... [avaliar] para ver se o tipo de trabalho que está fazendo está de fato atingindo os alunos. ... A avaliação deve servir para isto: para que o professor capte as necessidades do aluno em termos de aprendizagem, e/ou as suas necessidades em termos de ensino ... " (p. 88).

Mais ainda, é processando desse modo a avaliação da aprendizagem escolar que se poderá realizar uma compreensão mais realística da maior ou menor efetividade das metodologias de ensino disponíveis em promover a superação de desvios de aprendizagem observados.

Assim, pois, a avaliação da aprendizagem escolar, em seu caráter formativo, deve se processar contínua, cumulativa e sistematicamente, desde o início e durante todo o processo educacional, permeando as demais práticas pedagógicas - o 
planejamento e a implementação do processo de ensinoaprendizagem - que justificam esse processamento e que por ele são justificadas em suas naturezas e procedimentos, influenciando-se mutuamente e interagindo entre si no sentido de transformação para correta adequação e atendimento às necessidades e características de todos os alunos.

Para adaptar o ensino, então, não basta mais, por exemplo, reexplicar, desacelerar o ritmo, voltar para trás ou adotar um modo mais concreto de exposição. Todo público escolar, por mais selecionado que seja, é heterogêneo. Defrontados com o mesmo ensino, os alunos não progridem no mesmo ritmo e da mesma maneira. Caso se aplique uma avaliação formativa, cedo ou tarde sobrevém um momento em que é preciso render-se à evidência: nenhum ajuste global corresponde à medida da diversidade das necessidades. A única resposta adequada é a de diferenciar o ensino. .... É inútil insistir sobre a avaliação formativa onde os professores não têm nenhum espaço de jogo, onde a diferenciação não é senão um sonho jamais realizado, porque as condições de trabalho, o efetivo das classes, a sobrecarga dos programas, a rigidez dos horários ou outras exigências fazem do ensino frontal uma fatalidade, ou quase.

Praticada com uma certa constância, a avaliação formativa incita à diferenciação. Se esta última se chocar com uma resistência insuperável, seguir-se-ão conflitos e frustrações, portanto, uma regressão a métodos de ensino e de avaliação mais conforme às exigências dos professores. Há, em todo ator social, uma vontade de não saber aquilo com o que ele não pode fazer nada. .... É, portanto, pouco razoável, tanto em teoria quanto na prática, pleitear uma avaliação formativa sem se preocupar imediatamente com o espaço de jogo de que dispõem os professores, de fato ou de direito, em 
uma organização escolar especial. Se eles não têm, ou pensam não ter, possibilidades de diferenciação, não há razão alguma que os engaje em uma avaliação formativa, que não lhes deixará senão amarguras ou frustrações. Saber mais sobre seus alunos, o que eles dominam, a maneira como aprendem só é motivador quando se pode reinjetar imediatamente uma parte dessas informações na ação pedagógica .... Toda prática de avaliação formativa em aula [deve passar] por uma apropriação e uma reconstrução das intenções, bem como dos processos, que nenhum reformador, nenhum formador podem "programar" inteiramente do exterior .... Enquanto um professor não se concebe como alguém capaz de fazer todo mundo aprender - com a condição de se entregar a isso de maneira adequada - não tem razão alguma para se interessar pela avaliação formativa. Enquanto um professor julga que o fracasso está "na ordem das coisas", que há bons e maus alunos, que seu trabalho é o de dar aulas e não o de assegurar uma regulação individualizada dos processos de aprendizagem, os mais sofisticados modelos de avaliação formativa continuarão sendo indiferentes para ele. Perrenoud (1999, pp. 121-2)

Fecha-se, portanto, o ciclo, no qual os processos de avaliação formativa da aprendizagem escolar, de ensinoaprendizagem e de planejamento, são resgatados e contemplados em termos de relações próprias de reciprocidade e complementaridade entre eles, e desse modo configuram um processo pedagógico dinâmico em função da diversidade de alunos que dele participam, em função da melhoria da qualidade da educação para todos, sem a ninguém excluir; enfim, em função do desenvolvimento e implementação de um 
sistema educacional que contempla encaminhamentos para transformação social.

\section{Considerações Finais}

Desenvolvendo-se reflexões analítico-críticas das características do processo pedagógico convencionalmente realizado em nossas escolas, verificou-se que ele reflete a concepção liberal-conservadora da sociedade, cujo objetivo é conservá-la na sua configuração; e, por isso, em suas práticas pedagógicas, implícita ou explicitamente, mantém os alunos consistentes e estáveis ao longo do tempo, quer como pessoa quer como aluno, em seus diferenciados e "perpetuados" níveis de consecução de desenvolvimento-aprendizagem, "perpetuados" desde que aceitos como dados e nunca considerados intencionalmente como objeto de otimização. Precipuamente a avaliação da aprendizagem é usualmente entendida como causa dos resultados que verifica e da interpretação a eles dada em termos de "fracasso" ou "sucesso". Nesses termos ela é tratada, tanto no plano conceitual quanto no plano operacional, em desarticulação com o planejamento e processamento do ensino-aprendizagem.

Em confronto, um entendimento teórico-transformador da sociedade e de uma coerentemente adequada concepção de processo pedagógico, voltado para uma educação de qualidade para todos, indicou, inicialmente, a solidez das suposições básicas em que se fundamenta. Em segundo lugar, no entanto, identificou-se uma determinada tendência de superestimação da avaliação da aprendizagem como o elemento preponderante, e, por vezes, até mesmo exclusivo para a superação da questão do fracasso escolar, manisfestada nos altos índices de reprovação, repetência e evasão, bem como para a promoção de uma educação de qualidade para todos. 
Em outras palavras, a avaliação da aprendizagem, é geralmente, consciente ou inconscientemente, enfocada, de modo explícito, em si mesma, em suas características e mazelas, sem que esteja direta e explicitamente articulada com as práticas do planejamento e do processo de ensino-aprendizagem..

A partir daí tentou-se demonstrar que planejamento, processamento do ensino-aprendizagem e a avaliação da aprendizagem interagem em seus significados, em seus fins e em seus efeitos simultâneos e integrados, através de íntimas relações de reciprocidade e de complementariedade, sobre e para a ocorrência efetiva da aprendizagem para todos e consequentemente sobre a minimização do fracasso, as quais não decorrerão primeira e principalmente de uma "mudança de cultura avaliativa", e sim demandarão mais básica e abrangente mudança de cultura pedagógica. Ou seja, na medida em que a avaliação da aprendizagem reflete a ideologia subjacente à prática do planejamento e do processo de ensinoaprendizagem, bem como os correspondentes princípios e metodologias, então, qualquer proposta de modificação da prática vigente de avaliação educacional deveria, concomitante e necessariamente, incluir propostas coerentemente pertinentes de modificação das práticas atuais de planejamento e de processo de ensino-aprendizagem. Tudo isso centrar-se-ia em torno da compreensão de que a discussão e proposição metodológica de "como fazer a educação" deve processar-se em harmônica e efetiva articulação de todos os aspectos envolvidos neste "como fazer", e deles com "o para que fazer e o que fazer pedagógico" (Luckesi, 1996; Paulo, 1995; entre outros). 
No nível operacional ${ }^{3}$, trata-se de um processo pedagógico transformador, de encaminhamentos democráticos, que se desenvolve através de:

- Planejamento do processo de ensino-aprendizagem que inclui, pelo menos, a) definição clara de indicadores de desempenho de aprendizagens, nos quais são especificados as competências, as habilidades e os conteúdos do saber escolar desejados e necessários de serem desenvolvidos e construídos/re-construídos, que enfocam, sobretudo, a construção/re-construção dos conhecimentos sócio-historicamente produzidos, e que servem de critérios para a avaliação de aprendizagens realizadas, em processo de realização ou por serem ainda realizadas; b) os correspondentes métodos e as técnicas particulares de ensino, que, pelo menos em dado momento, são considerados adequados para promover a consecução, pelos alunos, daqueles indicadores de desempenho de aprendizagem.

> Por esses seus elementos constituintes, em suas características e funções, o planejamento do processo de ensino-aprendizagem reveste-se das propriedades de transparência e dinamicidade. Ele é transparente porque é compartilhado com os alunos, de acordo com o direito que lhes é básico de estarem cientes do que têm a aprender e dos mecanismos que atualmente se propõe como adequados para que realizem, efetivamente, essas aprendizagens em suas plenitudes.

\footnotetext{
${ }^{3}$ Uma abordagem analítico-crítica, no plano conceitual, das interrelações entre o planejamento, o processo de ensino-aprendizagem e a avaliação da aprendizagem, é contemplada em Luckesi (1995), nas pp. 120-167, Capítulo VII "Por uma prática docente crítica e construtiva" e Capítulo VIII - "Planejamento, Execução e Avaliação no Ensino: a busca de um desejo".
} 
Ele é dinâmico porque se modifica e varia de acordo com os conhecimentos prévios dos alunos, suas realidades sócio-econômicas e culturais, suas linguagens, seus modos próprios de processar as aprendizagens e desenvolver as competências definidas como desejadas-necessárias de serem por eles construídas/re-construídas, bem como de acordo com a extensão em que essas aprendizagens e competências são desenvolvidas e a qualidade com que são desenvolvidas, ao longo do processo de ensinoaprendizagem por cada um dos alunos. Acrescente-se ainda a incorporação de desempenhos e aprendizagens desejados de serem processados pelos próprios alunos, de acordo com seus interesses e motivações intrínsecos e extrínsecos.

> Processo de ensino-aprendizagem realizado em função da consecução, por todos, dos indicadores de desempenho de aprendizagem previamente definidos no seu planejamento e daqueles que são incorporados em vista dos interesses e motivações dos alunos, pela utilização de diversidade de tratamentos de ensinoaprendizagem em função das diversidades de alunos em suas correspondentes características e necessidades de modos de desenvolvimento. Em sendo esse o objetivo maior do processo de ensino-aprendizagem, então, necessariamente, ele é recorrentemente realizado com base na evidenciação da consecução ou não dos indicadores de desempenho, de modo diversificado, mas contínuo e sistemático ao longo do tempo em que se dão as práticas pedagógicas. E, portanto, é também transparente naqueles mesmos termos. 
- Avaliação da aprendizagem realizada no espírito da avaliação formativa, com base nos indicadores de desempenho de aprendizagens definidos $e$ incorporados ao planejamento e realização do processo de ensino-aprendizagem, diversificadamente em seus instrumentos, e de modo contínuo, cumulativo e sistematicamente desde o início e ao longo do processo pedagógico, pelo diagnóstico constante de conhecimentos prévios e atuais dos alunos durante $o$ continuum de realizações do ensino e das aprendizagens e pelas tomadas de decisão incidentes sobre os mais adequadamente corretos procedimentos de ensino-aprendizagens que fomentem a consecução daqueles indicadores de desempenho. Assim é que a avaliação da aprendizagem configura o componente do processo pedagógico que envolve e modifica os demais componentes desse processo - o planejamento e o processo de ensino-aprendizagem -, sendo, na mesma intensidade, por esses envolvida e modificada em seus objetos de julgamento de valor e de tomadas de decisão. Novamente, segue-se que a avaliação da aprendizagem, numa perspectiva de educação de qualidade para todos, é necessariamente transparente como o são o planejamento e a implementação do processo de ensino-aprendizagem.

Finalmente, cumpre observar que, no contexto da educação escolar transformadora, ainda se admite a realização da avaliação numa perspectiva de avaliação somativa, de caráter terminal em momentos determinados, orientada para classificação de alunos, tratamentos de ensino-aprendizagem e de professores, como forma de controle social, de oportunização de novas ou modificadas oportunidades 
educacionais, e de mecanismo de responsabilização das instituições educacionais formais e atores nelas envolvidos pela qualidade de ensino-aprendizagem escolar processado. Daí, a utilização de figuras quantitativas e/ou qualitativas para, em determinados pontos do continuum do processo pedagógico, relativamente distantes entre si (e por isso "terminais"), indicar a extensão em que os desempenhos e as aprendizagens foram mais ou menos desenvolvidas-realizadas nos níveis desejados e necessários sócio-historicamente.

\section{Referências Bibliográficas}

ANDRÉ, M.E.D.A. Avaliação da Escola e Avaliação na Escola. Cadernos de Pesquisa, V. 74, 1996.

BENDER, T. A pesquisa de interação entre aptidão e treinamento instrucional e sua aplicabilidade nas situações de ensino. Dissertação de Mestrado, Rio de Janeiro: Pontifícia Universidade Católica do Rio de Janeiro, 1980.

CANDAU, V. M. A didática e a formação de educadores - da exaltação à negação: a busca da relevância. In: CANDAU, V. M. (ed.) A didática em questão. (13a. Ed.) Petrópolis : Vozes, 1996.

CANDAU, V. M. A formação de educadores: uma perspectiva multidimensional. In: CANDAU, V. M. (ed.) Rumo a uma nova didática. (7a. Ed.) Petrópolis : Vozes, 1995. 
CHOPPIN, B. Evaluation, assessment and measurement. In: HUSEN, T. and POSTLETHWAITE T. N. (eds.) The international encyclopedia of education: research and studies. Oxford: Pergamon Press, 1985.

COLL, C. Aprendizagem escolar e construção do conhecimento. Porto Alegre, Artes Médicas, 1994.

DAVIS, C. e ESPÓSITO, Y. L. Papel e Função do Erro na Avalição Escolar. Cadernos de Pesquisa, (74), 1990.

DEMO, P. Avaliação qualitativa. São Paulo, Cortez, 1988.

GOVERNO DO ESTADO DE PERNAMBUCO. Plano Estadual de Educação - 1988-1991. Recife, Secretaria de Educação de Pernambuco, Inojosa, 1988.

GOVERNO DO ESTADO DE PERNAMBUCO. Política de ensino e escolarização básica. Recife: Secretaria de Educação e Esportes, 1998.

GOVERNO DO ESTADO DE PERNAMBUCO. Projeto político pedagógico da escola: organização da prática pedagógica em série ou ciclos - por que essa discussão?. Recife: Secretaria de Educação e Esportes, 1996a

GOVERNO DO ESTADO DE PERNAMBUCO. Plano Estadual de Educação - 1996-1998. Recife, Secretaria de Educação de Pernambuco, 1996b.

GOVERNO DO ESTADO DO PARANÁ. Secretaria de Estado da Educação. Política estadual de avaliação escolar . Relatório de Pesquisa, Curitiba, 1994.

GUBA, E. G. and LINCOLN, Y. S. Effective evaluation. San Francisco: Jossey-Bass, 1981.

HOFFMANN, J. Avaliação mediadora. Uma prática em construção da pré-escola à universidade. Porto Alegre, Educação e realidade, 1993.

HOFFMANN, J. Avaliação, mito e desafio. uma perspectiva construtivista. Porto Alegre, Educação e realidade, 1994. 
LELIS, I. A. A prática do educador: compromisso e prazer. In: CANDAU V. M. (ed.) Rumo a uma nova didática. (7a. Ed.) Petrópolis: Vozes, 1995.

LEWY, A. A função da avaliação (in Hebrew). In S. Eden (ed.) On the New Curricula. Tel-Aviv: Maaloth, 1971.

LEWY, A. and NEVO, D. (eds.) Evaluation roles in education. New York: Gordon and Breach, 1981.

LIBÂNEO, J.C. Didática. São Paulo: Ed. Cortez, 1994.

LUCKESI, C.C. O papel da didática na formação do educador. In: CANDAU V.M. (ed.) A didática em questão. (13a. Ed.) Petrópolis: Vozes, 1996.

LUCKESI, C. C. Avaliação da aprendizagem escolar. São Paulo: Cortez, 1994.

LÜDKE, M. Avaliando uma escola do $1^{\circ}$ grau. In: A construção do projeto de ensino e avaliação. Série Idéias $n^{0}$ 8. São Paulo, 1990.

LÜDKE, M e MEDIANO, Z. (Coord.) Avaliação na escola do $\mathbf{1}^{\circ}$ grau. Campinas, SP: Papirus Editora, 1992.

MELLO, G. N. Fatores intra-escolares como mecanismo de seletividade no ensino de Ensino Fundamental. In: Educação e Sociedade. São Paulo: Cortez e Moraes, ano 1, no. 2, 1979.

MELLO, G. N. Cidadania e competitividade: desafios educacionais do terceiro milênio. (5a. Ed.) São Paulo: Cortez, 1996.

MILDNER, T. Comunicação Pessoal - Orientação de Monografia. Recife: UFPE, Centro de Educação, outubro 1998-fevereiro 1999.

MILDNER, T. Avaliação da Rede Pública Estadual de Ensino: resultados de avaliação do currículo atingido. Recife: Secretaria de Educação e Esportes de Pernambuco, 1998.

MILDNER, T. Avaliação da Rede Estadual - 1997. In: PORTO, Z.G. e MILDNeR, T. Avaliação da Rede Pública Estadual de 
Ensino. Recife: Secretaria de Educação e Esportes de Pernambuco, 1997.

MILDNER, T. Comunicação Pessoal - Consultoria à Diretoria de

Educação Escolar, Secretaria de Educação e Esportes de

Pernambuco. Recife: SEE-PE, 1996

MILDNER, T. A statewide assessment and evaluation of fourth grade mathematics delivery system. Jerusalem: Ministry of Education and Culture, Israel Curriculum Center, 1989.

MINISTÉRIO DA EDUCAÇÃO E DO DESPORTO. Plano decenal de educação para todos. 1993-2003. Brasília: 1993.

MINISTÉRIO DA EDUCAÇÃO E DO DESPORTO. Educação para todos: A conferência de Nova Deli. Brasília: 1994.

MINISTÉRIO DA EDUCAÇÃO E DO DESPORTO. Projeto de educação básica para o nordeste. Brasília: 1994.

MINISTÉRIO DA EDUCAÇÃO E DO DESPORTO, CONSELHO NACIONAL DE EDUCAÇÃO, CÂMARA DE EDUCAÇÃO BÁSICA. Diretrizes Curriculares Nacionais Para O Ensino Médio. Parecer CEB No.15/98, Relatora Conselheira Guiomar Namo de Mello, Aprovado EM 01/06/98. Brasilia: CNE - CEB, junho 1998.

MINISTÉRIO DA EDUCAÇÃO E DO DESPORTO, SECRETARIA DE EDUCAÇÃO FUNDAMENTAL. Os Parâmetros curriculares nacionais. Brasília: 1997.

NEVO, D. Avaliação vantajosa (em Hebraico). Israel: Mesada, 1989

NEVO, D. The conceptualization of educational evaluation: an analytical review of literature. Review of Educational Research, 1983, 53, 117-128.

OLIVEIRA L. A. Avaliação escolar: julgamento ou construção?

Petrópolis; Vozes, 1994. 
PAULO, I. A dimensão técnica da prática docente. In: CANDAU V. M. (ed.) Rumo a uma nova didática. (7a. Ed.) Petrópolis: Vozes, 1995.

PERRENOUD, P. Avaliação: da excelência à regulação das aprendizagens - entre duas lógicas. Porto Alegre: Artes Médicas Sul, 1999.

PORTO, Z.G. e MILDNER, T. Avaliação da Rede Pública Estadual de Ensino. Recife: Secretaria de Educação e Esportes de Pernambuco, 1997.

SARASON, S.B. The culture of the school and the problem of change. Boston: Allyn and Bacon, 1971.

SCRIVEN, M. The methodology of evaluation. In: STAKE R. E. (ed.) Perspective on curriculum evaluation. AERA Monograph Series on Curriculum Evaluation, No. 1. Chigago: Rand MaNally, 1967.

SOARES, M. Avaliação educacional e clientela escolar. In: PATTO, Maria Helena. S. Introdução à Psicologia escolar. São Paulo, T. A. Queiroz, 1981.

SOUSA, C. P. Descrição de uma trajetória na/da avaliação Educacional. Série Idéias, ${ }^{\circ}$ 30. São Paulo, 1998.

SOUSA, C. P. (org.) Avaliação do rendimento escolar. Campinas, SP: Papirus Ed. 1995 (a).

SOUSA, C. P. Avaliação de rendimento escolar - Sedimentação de significados. In: SOUSA, C. P. (org.) Avaliação do rendimento escolar. Campinas, SP: Papirus Ed. 1995 (b).

SOUZA, S. Z. L. A prática avaliativa na escola de $1^{\circ}$ grau. In: SOUSA, C. P. (org.) Avaliação do rendimento escolar. Campinas, SP: Papirus Ed. 1995. 
SOUZA, S. Z. L. Avaliação da aprendizagem: Teoria, legislação e prática do cotidiano de escolas do $1^{\circ}$ grau. In: A construção do projeto de ensino e avaliação. Série Idéias, $n^{\circ} 8$. São Paulo, 1990.

SOUZA, S. Z. L. Avaliação da aprendizagem: Simpósio Nacional sobre Avaliação Educacional: uma reflexão crítica - Anais. Rio de Janeiro: Fundação CESGRANRIO, 1993.

STAKE, R. E. The countenance of educational evaluation. Teachers College Record, April 1967, 68(7), 523-540.

STUFFLEBEAM. D. L. Evaluation as enlightment for decision making. In: BEATTY, M. W. H. (ed.) Improving educational assessment and an inventory of measures of affective behavior. Washington, D.C.: Association for Supervision and Curriculum Development, 1969.

STUFFLEBEAM, D. L. et al Educational evaluation and decision-making. Itasca, Ill: Peacock, 1971.

VASCONCELOS, C. dos S. Algumas observações sobre a mudança na prática da avaliação. Avaliação: novos paradigmas. Revista da AEC. Ano 24, nº 94, 1995.

VASCONCELOS, C. dos S. A participação do professor na distorção da avaliação. Dois Pontos, V. II, Nº 13, 1992.

VASCONCELOS, I. A metodologia enquanto ato político da prática educativa. In: CANDAU, V. M. (ed.) Rumo a uma nova didática. (7a. Ed.) Petrópolis: Vozes, 1995.

WEBER, S. (org.) Democratização, educação e cidadania Caminho do Governo Arraes (1987-1990). São Paulo: Cortez, 1991.

WEBER, S. (org.) Sociedade e educação. alguns aspectos para debate. Recife: Ed. Universitária da UFPE, 1993.

WORTHEN, B. and SANDERS, J. R. Educational evaluation: theory and practice. Washington, D.C.: C. A. Jones, 1973. 